\title{
RETRACTED ARTICLE: Three New Structures for Reactive Power Market by Considering Reactive Losses Caused by the Active Power Flow
}

\author{
A. Ahmadimanesh ${ }^{1} \cdot$ M. Kalantar ${ }^{1}$
}

Received: 16 March 2017 / Accepted: 15 April 2019 / Published online: 7 May 2019

(c) Shiraz University 2019

The Editor-in-Chief has retracted this article [1] because it significantly overlaps with previously published articles by the same authors [2,3]. Alireza Ahmadimanesh does not agree to this retraction. Mohsen Kalantar has not responded to any correspondence from the publisher about this retraction. The online version of this article contains the full text of the retracted article as electronic supplementary material.

\section{References}

[1] Ahmadimanesh A, Kalantar M (2019) Three new structures for reactive power market by considering reactive losses caused by the active power flow. Iran J Sci Technol Trans Electr Eng. https ://doi.org/10.1007/s40998-019-00195-6

[2] Ahmadimanesh A, Kalantar M (2017) Two new frameworks for reactive power market considering reactive losses. Int Trans Electr Energ Syst 27:e2387. https://doi.org/10.1002/etep.2387

[3] Ahmadimanesh A, Kalantar M (2017) A novel cost reducing reactive power market structure for modifying mandatory generation regions of producers. Energy Policy 108:702-711. https://doi. org/10.1016/j.enpol.2017.06.046

Electronic supplementary material The online version of this article (https://doi.org/10.1007/s40998-019-00195-6) contains supplementary material, which is available to authorized users.

A. Ahmadimanesh

alireza_ahmadimanesh@elec.iust.ac.ir

M. Kalantar

kalantar@iust.ac.ir

1 Center of Excellence for Power Systems, Automation and Operation, Iran University of Science and Technology,

Tehran, Iran 